\title{
ERRATUM
}

\section{INTEGRATED SYSTEMS AND OUTSOURCING: PROCESS INNOVATION IN AEROSPACE PRODUCT DESIGN}

\author{
[International Journal of Innovation and Technology Management (IJITM) \\ Vol. 9, No. 3 (2012) 1250019]

\section{NOUHA TAIFI} \\ Mohammadia School of Engineering \\ Industrial Engineering Department \\ University Mohammed V, Rabat, s.n. 10090 \\ Morocco and Center for Business Innovation \\ Università del Salento, Via per Monteroni, Lecce, s.n. 73100, Italy \\ taifi@emi.ac.ma \\ MARIANGELA LAZOI \\ Innovation Engineering Department and Center for Business Innovation \\ Università del Salento, Via per Monteroni \\ Lecce, s.n. 73100, Italy \\ mariangela.lazoi@ebms.unile.it

\section{ANGELO CORALLO* ${ }^{*}$ and GIUSEPPINA PASSIANTE ${ }^{\dagger}$} \\ Department of Innovation Engineering \\ University of Salento, Via per Monteroni \\ Lecce, s.n. 73100, Italy \\ *angelo.corallo@ebms.unile.it \\ †'giuseppina.passiante@ebms.unile.it

\section{MARIANGELA LAZOI} \\ Head of Information Systems Department-Responsible of the Architecture \\ Innovation and Benchmarking, Alenia Aeronautica SpA \\ Finnmeccanica Group Services, Rome, Italy \\ mmonaco@alenia.it
}

Published 26 September 2012

The correct affiliation of the last author should read as

\section{MICHELE MONACO}

Head of Information Systems Department-Responsible of the Architecture Innovation and Benchmarking, AleniaAeronauticaSpA

Finnmeccanica Group Services, Rome, Italy

mmonaco@alenia.it 